\title{
Real-time co-site optical microscopy study on the morphological changes of the dentine's surface after citric acid and sodium hypochlorite: a single-tooth model
}

\author{
Wojciech Wilkoński ${ }^{*} \mathbb{0}$, Lidia Jamróz-Wilkońska' ${ }^{1}$ Szczepan Zapotoczny ${ }^{2}$, Janusz Opiła ${ }^{3}$ and Luciano Grandino ${ }^{4}$
}

\begin{abstract}
Background: To this day, the effects of sodium hypochlorite and chelating agents on the smear layer and on the dentine's surface, remain not fully examined. The study is aimed to analyze the dentine's surface treated with $40 \%$ citric acid and 5.25\% sodium hypochlorite according to two irrigation protocols.

Materials and methods: The study employed a computer-controlled Nikon Eclipse LV100 optical microscope. Ten roots split longitudinally with canals prepared mechanically using the MTwo system to a size of 40/04 were observed. The root halves were divided into two study groups, one half in each of the groups. According to two irrigation protocols, the dentine's surface was irrigated with $40 \%$ citric acid and 5.25\% sodium hypochlorite, separated with water. Dentine surface was observed in a fixed place and photographed in $500 \times$ magnification after each irrigation stage. The obtained images were then analyzed using computer software (NIS-Elements AR, GIMP-2.6, ImageJ 1.45s).

Results: Various speed of removal of the smear layer and varied morphological changes of the dentine's surface were observed in both examined groups. Double irrigation of the dentine with citric acid for $30 \mathrm{~s}$ resulted in complete removal of the smear layer, and double irrigation for 60 s resulted in increased mean diameter of the dentine tubules (degradation of the dentine's surface).

Conclusions: Double alternating irrigation with citric acid and sodium hypochlorite for 30 s yielded satisfactory results, while double irrigation for $60 \mathrm{~s}$ resulted in increased mean diameter of the dentine tubules. A real time assessment of the dentine's surface changes after both tested solutions can improve understanding of the phenomena that occur during the irrigation and as a result it might help to improve clinical outcomes in root canal treatment.
\end{abstract}

Keywords: Sodium hypochlorite, Citric acid, Root canal, Irrigation, Smear layer, Demineralization, Dentine

\section{Background}

During the endodontic treatment, the smear layer is created due to the mechanical preparation of root canals. It covers canal walls and closes dentinal tubules [1]. Smear

\footnotetext{
*Correspondence: wilkonski@onet.eu

1 Research Department of the Polish Endodontic Association, Kielce, Poland

Full list of author information is available at the end of the article
}

layer removal of the from the root canal is controversial. On the one hand, removing the smear layer increases dentine's permeability and, as a result, penetration of antiseptics and sealers for dentinal tubules. On the other hand, however, it causes changes in the chemical composition and physical properties of the dentine. Chelating agents are commonly used for the removal of the inorganic component of the smear layer. They also cause demineralization of the dentine, resulting in exposure 
of collagen fibers and dentinal surface erosion. Uneven dentine's surface has a negative effect on the adaptation of the material obturating root canals, and the collagen matrix is not thoroughly hybridized with sealers $[2,3]$. The resulting micro-and nano-leakage can potentially negatively affect the results of endodontic treatment [4].

The majority of academic papers concerning the surface of root canal walls are based on studies using a Scanning Electron Microscope (SEM). Such studies have numerous flaws: a specimen is processed with chemicals, dehydrated with alcohol, and coated with a nanoscale layer of metal, then observed in a high vacuum. Hydrated organic structures collapse during dehydration of specimens for testing [4]. De-Deus et al. described test methods using an optical microscope as an alternative to SEM tests [5-7]. Such tests provide an image of the sample surface in a water environment without damaging the sample. The samples can be observed during irrigation, obtaining real-time images. Concerning such possibilities, an experiment was carried out to analyze changes in the dentine's surface caused by irrigation fluids commonly used in endodontics.

\section{Methods}

According to two irrigation protocols, the study aimed to analyze the dentine's surface immediately after irrigation with citric acid and sodium hypochlorite.

The study included ten human upper canines removed due to periodontal problems. The teeth after extraction were stored in $1 \%$ solution of chloramine. After cleaning the roots, anatomical crowns were cut off using drills with diamond coating and water-air cooling. Root canals were prepared using the Mtwo system to a size of 40 taper 04 using "crown-down" technique following with the previously described sequence [8]. Following preparation of the root canals, the canals were irrigated with $5.25 \%$ sodium hypochlorite for $1 \mathrm{~min}$. The roots were then incised longitudinally using discs with doublesided diamond coating and constant water-air cooling, then split with a chisel into two halves with similar sizes. The halves were then divided into two study groups. The roots were placed on the platform of Nikon Eclipse LV100 (Nikon, Japan) optical microscope one by one and central parts of root canals in the most representative spot were observed in $500 \times$ magnification. Output image of the root surface was recorded before irrigation. Maintaining the same position of specimens, the canals were irrigated according to the following protocols:

- Group 1:

- Stage 1: $30 \mathrm{~s}-40 \%$ citric acid,

- Stage 2: $30 \mathrm{~s}-5.25 \%$ sodium hypochlorite,
- Stage 3: $30 \mathrm{~s}-40 \%$ citric acid,

- Stage 4: $60 \mathrm{~s}-5.25 \%$ sodium hypochlorite,

- Group 2:

- Stage 1: $60 \mathrm{~s}-40 \%$ citric acid,

- Stage 2: $30 \mathrm{~s}-5.25 \%$ sodium hypochlorite,

- Stage 3: $60 \mathrm{~s}-40 \%$ citric acid,

- Stage 4: $60 \mathrm{~s}-5.25 \%$ sodium hypochlorite,

After each subsequent irrigation stage, the canals were thoroughly washed with distilled water in order to stop chemical reactions, and then immediately observed in $500 \times$ magnification.

\section{Obtaining images and measurements}

Each specimen was observed before recording images and conducting the study. Each observation with manual adjustment of the microscope platform was aimed at determination of limit points of the distance between the specimen and the lens ensuring sharp image of the specimen. Such parameters were then entered into to the computer software NIS-Elements AR (NIS-Elements, USA). A computer-controlled digital camera took 30-90 pictures in $2560 \times 1920$ resolution with moving the sample away from the lens in $0.5 \mu \mathrm{m}$ increments within the determined limits. The aggregate images of the canal dentine's surface were obtained by superimposing several dozens of images with a total resolution of $0.14 \mu \mathrm{m} /$ pixel, whereas the computer software used the algorithm for selective superimposition of fragments of images with sharp contours. The obtained images were saved to graphic file formats and subject to further processing and measurement using GIMP-2.6 (GIMP Development Team) and ImageJ $1.45 \mathrm{~s}$ (National Institutes of Health, USA) software done by blinded observer (WW) after encoding data. For the purposes of the analysis, the files were converted to 8-bit version, then binarized so that the open dentinal tubules were visible as circles and ovals. The following parameters were analyzed and measured:

- changes in the diameter of open dentinal tubules,

- effectiveness of smear layer removal.

Diameters of dentinal tubules were determined on the basis of measurements in ImageJ 1.45s application. Diameters of all the dentinal tubules, whose full circumference was contained in the area of $100 \times 100 \mu \mathrm{m}$ in the central point of the image, were calculated. The averaged values together with standard deviation were taken into consideration in the statistical analysis. 
The smear layer removal was evaluated upon the measurement of the percentage of opened dentinal tubules measured via software (ImageJ). A five-degree scale was used to assess the efficiency of smear layer removal:

1-no smear layer-all the dentinal tubules were open,

2 -a small area covered with the smear layer $(>75 \%$ of the dentinal tubules were open),

3 -the smear layer partially covering the dentine (50-75\% of the dentinal tubules were open),

4-the smear layer covering the dentine to a large extent (10-49\% of the dentinal tubules were open),

5-the smear layer completely covering the dentine $(<10 \%$ of the tubules were open).

The data was gathered in a database, decoded (after evaluation by blinded observer) and subjected to statistical analysis using the following tests: Kruskal-Wallis' test, sign test and U Mann-Whitney's test, with statistical significance set at $p \leq 0.05$ (Table 1 ).

\section{Results}

In group 1, following the first stage of irrigation (citric acid for $30 \mathrm{~s}$ ), no effective removal of the smear layer was observed-10\% of the canals were cleaned to the degree 1, 50\%-degree 2 and 40\%-degree 3 and 4 . In group 2, after the first irrigation stage (citric acid for $60 \mathrm{~s}$ ), 30\% of the canals were cleaned to the degree $1,60 \%$-to the degree 2 and $10 \%$-degree 3 . Differences in the degree of removal of the smear layer between the groups after the first stage of irrigation were not statistically significant $(p=0.13)$. However, statistically significant differences in the diameter of the dentinal tubules were identified $(p=0.004)$. After the second stage of irrigation (sodium hypochlorite for $30 \mathrm{~s}$ ), improved degree of removal of the smear layer from the canal walls was observed in both groups. In group 2 canals, there were more canals with the smear layer removed than in group 1, however, the differences were not statistically significant $(p=0.36)$. Also, in both groups, an increase of the diameter of dentinal tubules was observed and such changes were statistically significant $(p=0.004)$. After the third irrigation stage (citric acid for $30 \mathrm{~s}$ in group 1 and $60 \mathrm{~s}$ in group 2 ), further improvement of the smear layer removal and a further increase in the dentine tubules' diameter were observed. No statistically significant differences were observed between the two groups concerning smear layer removal $(p=0.71)$, however, the differences in diameters of the dentinal tubules between the groups were statistically significant $(p=0.004)$. Statistically significant differences between group 1 after the third irrigation cycle and group 2 after the first irrigation cycle were observed (total irrigation time with citric acid-60 s) both with regard to the level of smear layer removal and diameters of the dentinal tubules $(p=0.02 ; p=0.00$, respectively). After the fourth irrigation stage (sodium hypochlorite for $60 \mathrm{~s}$ ), the same percentage of canals with smear layer entirely removed. An increase of the diameters of dentinal tubules was observed in both groups. In contrast, in group 2, the dentinal tubules' diameter was statistically significantly larger $(p=0.004)$. The data have been presented in Tables 1, 2 and 3.

\section{Discussion}

Removal of the smear layer is a commonly recommended procedure. However, no evidence could prove that removing the smear layer is necessary for better results of endodontic treatment. The abundance of factors affecting the treatment results makes it very difficult to obtain statistically significant differences in such clinical studies. The primary goal of endodontic treatment in infected teeth is to remove pathogens and the complete root canals obturation. The studies show that pathogens

Table 2 Diameters $[\mu \mathrm{m}]$ of dentine tubules (mean $\pm \mathrm{SD}$ ) in experimental groups after four irrigation stages

\begin{tabular}{lllll}
\hline & Stage 1 & Stage 2 & Stage 3 & Stage 4 \\
\hline Group 1 & $3.68 \pm 0.06$ & $4.13 \pm 0.06$ & $4.35 \pm 0.05$ & $5.10 \pm 0.08$ \\
Group 2 & $3.92 \pm 0.06$ & $4.78 \pm 0.08$ & $4.97 \pm 0.08$ & $5.82 \pm 0.10$ \\
\hline
\end{tabular}

Table 1 Statistical tests used to calculate the significance of the differences between both experimental groups

\begin{tabular}{|c|c|c|c|c|c|c|c|c|c|c|c|}
\hline \multirow[t]{2}{*}{ Test used } & \multirow[t]{2}{*}{ Parameter tested } & \multicolumn{2}{|c|}{$\begin{array}{l}\text { Stage } 1 \\
\text { Gr } 1 \text { vs Gr } 2\end{array}$} & \multicolumn{2}{|c|}{$\begin{array}{l}\text { Stage } 2 \\
\text { Gr } 1 \text { vs Gr } 2\end{array}$} & \multicolumn{2}{|c|}{$\begin{array}{l}\text { Stage } 3 \\
\text { Gr } 1 \text { vs Gr } 2\end{array}$} & \multicolumn{2}{|c|}{$\begin{array}{l}\text { Stage } 4 \\
\text { Gr } 1 \text { vs Gr } 2\end{array}$} & \multicolumn{2}{|c|}{$\begin{array}{l}\text { Stage } 3 \mathrm{Gr} 1 \text { vs } \\
\text { Stage } 1 \mathrm{Gr} 2\end{array}$} \\
\hline & & $p$ & Z & $p$ & Z & $p$ & z & $p$ & z & $p$ & z \\
\hline Sign test & \multirow{2}{*}{$\begin{array}{l}\text { Changes of the diameters of } \\
\text { dentine tubules }\end{array}$} & 0.0044 & 2.846 & 0.0044 & 2.846 & 0.0044 & 2.846 & 0.0044 & 2.846 & & \\
\hline Mann-Whitney U & & & & & & & & & & 0.00 & -3.743 \\
\hline Mann-Whitney U & \multirow[t]{2}{*}{ Smear layer removal efficiency } & 0.143 & 1.629 & 0.393 & 0.981 & 0.739 & 0.453 & 1.00 & -0.073 & 0.024 & 2.258 \\
\hline Kruskal-Wallis & & 0.131 & & 0.364 & & 0.705 & & 1.00 & & & \\
\hline
\end{tabular}


Table 3 Smear layer scores in group 1 and 2 before and after four irrigation stages

\begin{tabular}{|c|c|c|c|c|c|c|c|c|c|c|}
\hline & \multicolumn{2}{|c|}{ Stage 0} & \multicolumn{2}{|c|}{ Stage 1} & \multicolumn{2}{|c|}{ Stage 2} & \multicolumn{2}{|c|}{ Stage 3} & \multicolumn{2}{|c|}{ Stage 4} \\
\hline & Gr 1 & Gr 2 & Gr 1 & Gr 2 & Gr 1 & Gr 2 & Gr 1 & Gr 2 & Gr 1 & Gr 2 \\
\hline Score 1 & 0 & 0 & 1 & 3 & 4 & 6 & 7 & 8 & 9 & 9 \\
\hline Score 2 & 0 & 0 & 5 & 6 & 5 & 4 & 3 & 2 & 1 & 1 \\
\hline Score 3 & 0 & 0 & 3 & 1 & 1 & 0 & 0 & 0 & 0 & 0 \\
\hline Score 4 & 0 & 0 & 1 & 0 & 0 & 0 & 0 & 0 & 0 & 0 \\
\hline Score 5 & 10 & 10 & 0 & 0 & 0 & 0 & 0 & 0 & 0 & 0 \\
\hline
\end{tabular}

can penetrate dentinal tubules up to $200 \mu \mathrm{m}$ [9]. Therefore, removing the smear layer is theoretically necessary to penetrate antiseptic agents and sealers into dentinal tubules.

Smear layer removal is a chemical reaction that takes place in a given time and space of the endodontic system. Recording phenomena related to such process is usually connected with the use of scanning electron microscopes (SEM). Preparation of SEM examination specimens consists of their gradual dehydration in a graded ethanol solution and coating them with a layer of precious metals. Then, samples are observed in high vacuum. Such specimens, as hydrated spatial structures, change both in volume and morphology. Proteins become denaturated with alcohol and collapse due to desiccation. Such images do not reflect subtle details of the dentine's surface and can lead to formulation of erroneous conclusions. Tay et al. modified the method of preparation of specimens by using silazane before application of metal in order to fill in spaces left after water [3]. As a result of such modification, images that differ significantly from the previously observed ones were obtained. Probably what had been considered dentine is actually collapsed collagen coated with metal. Therefore, the previous studies presenting alleged dentinal erosion resulting from treatment with sodium hypochlorite after chelating agents, actually present the image of the dentine after dissolution of exposed collagen [3]. This study also revealed changes in diameters of dentinal tubule orifices due to of lysis of the collagen with sodium hypochlorite. In other studies, Tay et al. proved that exposed collagen could be a potential source of problems as it cannot be thoroughly infiltrated with sealers. Tay et al. assumed that the use of hypochlorite after chelating agents can be beneficial for nanosealing ability, as application of chelating agents causes erosion of the dentine anyway [2].

Despite the progress in methodology and extreme precision of SEM examinations, real-time observation of processes is impossible. A specimen prepared for SEM examination is destroyed and its further chemical processing, examination, observation and comparative analysis before and after processing are not possible.
Therefore, it is necessary to prepare specimens after each cycle/method of irrigation. De-Deus et al. used an Atomic Force Microscope (AFM) to assess smear layer removal speed in real-time [10]. AFM examination provides an image of the sample surface in water environment without damaging the specimen. The same surface can be rinsed and analyzed again. The authors identified limitations of such method, mainly related to the scanning time of the specimen. In other studies, De-Deus et al. used a computer-controlled optical microscope and digital image processing [5-7]. This study employs optical microscope as well. Computer control and software ensured sharp images despite large differences in the distance between individual parts of canal walls and the lens. Similarly to De-Deus et al., this study uses two halves of the same tooth divided into two study groups (single tooth method) [6]. It ensures very similar qualitative distribution of specimen's dentine in the study groups.

This study employs a complex, five-degree scale assessing the effectiveness of smear layer removal, eliminating any possible contribution of subjective human nature. Precise measurements using computer software and division concerning the percentage share of open tubules also allow for assessment of the speed of smear layer removal after given irrigation cycles.

The studies show that the concentration of citric acid affects the speed of demineralization and smear layer removal effectiveness. In the study by Prado et al., $10 \%$ concentration was applied for 30, 60 and 180 s with better results in comparison with $17 \%$ EDTA [1]. However, Khedmat et al., also using $10 \%$ concentration of citric acid, obtained worse efficiency in the apical section than with $17 \%$ EDTA [11]. In this study, a $40 \%$ concentration with a total irrigation time of 60 and $120 \mathrm{~s}$ was used. No statistically significant changes in the eventual effectiveness of smear layer removal were found in both study groups. In the group irrigated with citric acid in two 60-s cycles, faster smear layer removal was observed. After the first 60-s cycle, the smear layer's reduction was identified in $30 \%$ of the specimens. In comparison, in group 1 , after the first 30-s cycle, the smear layer was removed in 


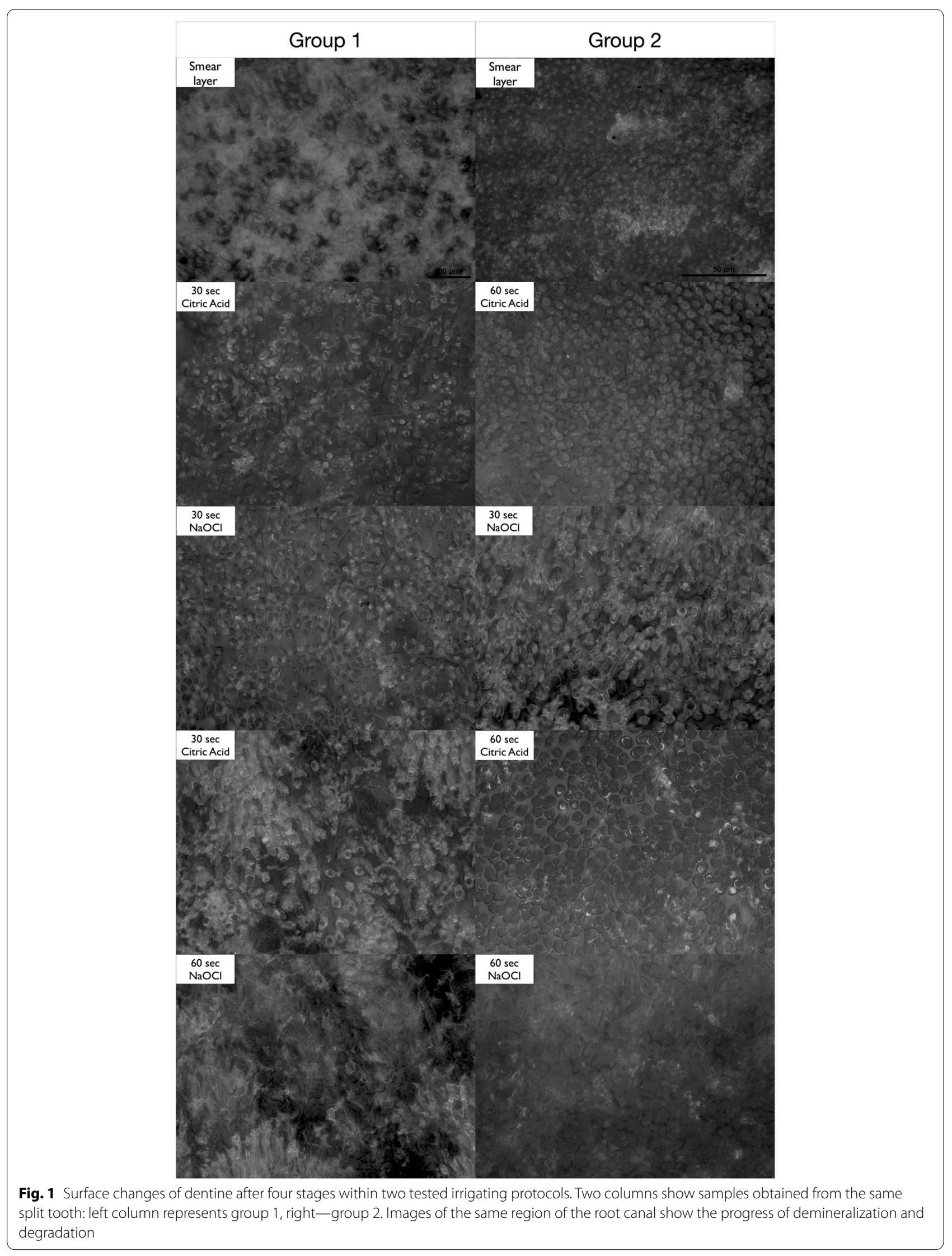


$10 \%$ of the samples. In both study groups, alternate irrigation with sodium hypochlorite dissolved demineralized tissue, increasing diameters of dentinal tubule orifices, and probably improved acid penetration in the following irrigation cycle. A higher percentage of canals with removed smear layer in group 1 after the third stage of irrigation in comparison with group 2 after the first irrigation stage (total time of citric acid activity-60 s) shows an improvement of the effectiveness of citric acid after the prior dissolution of organic compounds with sodium hypochlorite. In the second group, double 60-s irrigation with citric acid caused degradation of the dentine's surface reflected in the distortion of homogeneous structure and erosion of the tubules' edges. (Fig. 1). Therefore, despite limitations of the study, it can be concluded that double irrigation with citric acid after $30 \mathrm{~s}$ and $60 \mathrm{~s}$ was equally effective in removing the smear layer, and irrigation in two cycles $60 \mathrm{~s}$ each can result in increased diameter of the dentinal tubules, which might be perceived as undesired morphological changes on the dentine's surface. Such assumptions require further studies using different methodologies and imaging methods, considering limitations of fluid distribution and the varied dentine structure in individual parts of root canals.

Despite of the efforts, this experiment has limitations. There is a potential risk of sampling and distribution errors that can lead to distorted assessment of the results. This study is focused in the measurements (of the smear layer removal and diameter of the dentine's tubules) only in selected, flat regions of the root canal walls, not the entire the root canal. Thus, the gathered data may not reflect the true results. In this experiment, in order to achieve the precision, sensitivity and repeatability of the measurements, only straight root canals with simple anatomy were used. The outcomes in curved or oval/flat/ irregular root canals could be different. It should be also pointed out that the small sample size, while is sufficient enough to gain satisfactory laboratory results, may not be fully representative. It should be mentioned that this study cannot be directly referred to as a clinical situation because, during the irrigation of root canals, the fluid is administered with a needle and not perpendicularly to the dentine's surface (Additional file 1).

\section{Conclusions}

Upon this in vitro study, with its shortcomings, it may be concluded that double alternating irrigation with citric acid and sodium hypochlorite is an effective way of removing the smear layer. Cycles of $30 \mathrm{~s}$ each were sufficient to gain satisfactory results, while $60 \mathrm{~s}$ ones resulted in increased mean diameter of dentine tubules.
Abbreviations

AFM: Atomic force microscope; EDTA: Ethylenediaminetetraacetic acid; SEM: Scanning electron microscope.

\section{Supplementary Information}

The online version contains supplementary material available at https://doi. org/10.1186/s12903-021-01815-6.

Additional file 1. Detailed data is available in the additional file upon reasonable request (Additional file 1).

\section{Acknowledgements}

The research was carried out with the the equipment purchased thanks to the financial support of the European Regional Development Fund in the framework of the Polish Innovation Economy Operational Program (contract no. POIG.02.01.00-12-023/08).

\section{Authors' contributions}

WW and LJW designed this study. WW, LJW and JO wrote the manuscript. WW and SZ performed the laboratory work. WW, SZ and JO made the computations and acquisition of data. JO made the statistical analysis of the data. WW, LJW and LG made interpretation of data and developed the theory. LG made substantively revised and corrected the paper. All authors read and approved the final manuscript.

\section{Funding}

The research was carried out with the equipment purchased thanks to the financial support of the European Regional Development Fund in the framework of the Polish Innovation Economy Operational Program (contract no. POIG.02.01.00-12-023/08)

\section{Availability of data and materials}

The datasets used and/or analysed during the current study are available from the corresponding author on reasonable request.

\section{Declarations}

\section{Ethics approval and consent to participate}

This study was based on extracted human teeth due to the periodontal disease. All patients gave their verbal consent to use the extracted teeth in this experiment. According to The Silesian Medical University's Bioethics Committee decision number: KNW/0022/KB/83/09 state: this kind of research (in vitro study based on teeth extracted because of the disease) does not require additional consent from the committee as it is not in vivo medical experiment

\section{Consent for publication}

Not applicable.

\section{Competing interests}

The authors declare that they have no competing interests.

\section{Author details}

${ }^{1}$ Research Department of the Polish Endodontic Association, Kielce, Poland.

${ }^{2}$ Faculty of Chemistry of the Jagiellonian University, ul. Gronostajowa 2, 30-387 Kraków, Poland. ${ }^{3}$ Chair of Applied IT of the Faculty of Management of AGH University of Science and Technology, Kraków, Poland. ${ }^{4}$ Crotone, Italy.

Received: 22 May 2021 Accepted: 8 September 2021

Published online: 17 September 2021

\section{References}

1. Prado M, Gusman H, Gomes BP, Simão RA. Scanning electron microscopic investigation of the effectiveness of phosphoric acid in smear layer removal when compared with EDTA and citric acid. J Endod. 2011;37(2):255-8 
2. Tay FR, Hosoya Y, Loushine RJ, Pashley DH, Weller RN, Low DC. Ultrastruc ture of intraradicular dentin after irrigation with BioPure MTAD. II. The consequence of obturation with an epoxy resin-based sealer. J Endod. 2006;32(5):473-7.

3. Tay FR, Gutmann JL, Pashley DH. Microporous, demineralized collagen matrices in intact radicular dentin created by commonly used calciumdepleting endodontic irrigants. J Endod. 2007:33(9):1086-90.

4. Suchodolski Ł, Wilkoński W, Jamróz-Wilkońska L, Gabryś S, Krupiński J, Opiła J. Ocena wpływu protokołu płukania kanałów korzeniowych na szczelność wypełnień z gutaperki z dwoma uszczelniaczami - MTA Fillapex i 2Seal. Badanie in vitro. Mag Stomatol 7-8/2011; 149-155 (online)

5. De-Deus G, Reis CM, Fidel RA, Fidel SR, Paciornik S. Co-site digital optical microscopy and image analysis: an approach to evaluate the process of dentine demineralization. Int Endod J. 2007;40(6):441-52.

6. De-Deus G, Zehnder M, Reis C, Fidel S, Fidel RA, Galan J Jr, Paciornik S. Longitudinal co-site optical microscopy study on the chelating ability of etidronate and EDTA using a comparative single-tooth model. J Endod. 2008;34(1):71-5.

7. De-Deus G, Souza EM, Marins JR, Reis C, Paciornik S, Zehnder M. Smear layer dissolution by peracetic acid of low concentration. Int Endod J. 2011;44(6):485-90.
8. Wilkoński W, Zbożeń J, Zbożeń T, Jamróz-Wilkońska L. Porównanie opracowania kanałów korzeniowych za pomocą systemów rotacyjnych Mtwo i EndoWave oraz nowego systemu SAF - badanie in vitro. Magazyn Stomatologiczny. 2010;11:82-94.

9. Peters OA, Boessler C, Paqué F. Root canal preparation with a novel nickeltitanium instrument evaluated with micro-computed tomography: canal surface preparation over time. J Endod. 2010;36(6):1068-72.

10. De-Deus G, Paciornik S, Pinho Mauricio MH, Prioli R. Real-time atomic force microscopy of root dentine during demineralization when subjected to chelating agents. Int Endod J. 2006;39(9):683-92.

11. Khedmat S, Shokouhinejad N. Comparison of the efficacy of three chelating agents in smear layer removal. J Endod. 2008;34(5):599-602.

\section{Publisher's Note}

Springer Nature remains neutral with regard to jurisdictional claims in published maps and institutional affiliations.
Ready to submit your research? Choose BMC and benefit from:

- fast, convenient online submission

- thorough peer review by experienced researchers in your field

- rapid publication on acceptance

- support for research data, including large and complex data types

- gold Open Access which fosters wider collaboration and increased citations

- maximum visibility for your research: over $100 \mathrm{M}$ website views per year

At BMC, research is always in progress.

Learn more biomedcentral.com/submissions 